\title{
Survival in Cases of Intestinal Tumors
}

\author{
Maurício Daniel dos Santos ${ }^{10}$ Marissa Andrade Baldim ${ }^{10}$ Francine Neves ${ }^{1(0)}$ \\ Rafaela Rezende do Amaral Naves ${ }^{10}$ Karina Macedo Reis ${ }^{1 \odot}$ Thais Silva Ramos ${ }^{10}$ \\ Alessandra Cristina Pupin Silvério ${ }^{2}{ }^{\circ}$ Roberta Bessa Veloso Silva ${ }^{2} \odot$
}

\footnotetext{
${ }^{1}$ Students of the Course of Medicine of Medicine, Universidade José do Rosário Vellano (UNIFENAS), Alfenas, Minas Gerais, Brazil

${ }^{2}$ Teachers of Universidade José Rosário Vellano (UNIFENAS), Alfenas, Minas Gerais, Brazil

J Coloproctol 2021;41(4):335-339.
}

Address for correspondence Maurício Daniel dos Santos, Medicine undergraduate, Rodovia MG 179, Km 0, Trevo Bloco 05, Alfenas, MG, 37132-440, Brazil (e-mail: mauriciodss.2@hotmail.com).

\begin{abstract}
Objective To assess the survival rate of patients with colorectal cancer at Hospital Universitário Alzira Vellano, in the municipality of Alfenas, state of Minas Gerais (MG), Brazil, from 2007 to 2016.

Methodology A search was conducted in the laboratory files and medical records of patients diagnosed with colorectal cancer and cared for during the aforementioned period.

Results In total, 128 cases were found: $52.3 \%$ were men, and $47.7 \%$ were women, with ages ranging from 25 to 91 years. The most common types of cancer in both genders were of the colon, rectum and sigmoid. The most common stages were

Keywords

- cancer

- colon

- disease

- rectum T3N1Mx, followed by T3N0Mx and T3N2Mx. Patients with T1 or T2 cancers had a 100\% survival rate, whereas the rate for those with grade 4 (T4) was of $0 \%$. An association $(p<0.05)$ of the location of the tumor with the survival rate was confirmed.

Conclusion There was a high mortality rate among patients diagnosed with colorectal cancer at Hospital Universitário Alzira Vellano from 2007 to 2016.
\end{abstract}

\section{Introduction}

Cancer is a public health issue worldwide which has worsened lately, mainly due to the aging of the population in developing countries such as Brazil, ${ }^{1}$ where 685,960 new cases of cancer were estimated for $2020 .^{2}$

However, recently there has also been a great advance in the diagnosis and treatment of cancer, highlighting surgery, radiotherapy, chemotherapy, hormone therapy, immunotherapy and combined therapy as the main forms of treatment of the tumor. ${ }^{3}$ Therefore, regarding treatment planning. several factors must be taken into account, such as: age; nutritional status; renal, hepatic and pulmonary functions; the presence or absence of infections; the type of tumor; the presence of metastasis; and the patient's general health status. ${ }^{4,5}$

Among the different types of cancer, colorectal cancer is one of the most prevalent tumors, presenting high morbidity and mortality rates when diagnosed late. ${ }^{6}$ In Brazil, it has been estimated that in 2020 there would be 40,990 new cases, 20,520 in male patients and 20,470 in female patients. ${ }^{2}$

The survival rate is one of the statistical evaluations to verify the severity of tumors, and it indicates the percentage of patients who live at least 5 years after the diagnosis. However, many people live much longer than 5 years, and several get cured. ${ }^{7}$ One of the factors that can influence the received

September 10, 2020

accepted

January 18, 2021
DOI https://doi.org/

10.1055/s-0041-1730423.

ISSN 2237-9363. (c) 2021. Sociedade Brasileira de Coloproctologia. All rights reserved.

This is an open access article published by Thieme under the terms of the Creative Commons Attribution-NonDerivative-NonCommercial-License, permitting copying and reproduction so long as the original work is given appropriate credit. Contents may not be used for commercial purposes, or adapted, remixed, transformed or built upon. (https://creativecommons.org/ licenses/by-nc-nd/4.0/)

Thieme Revinter Publicações Ltda., Rua do Matoso 170, Rio de Janeiro, RJ, CEP 20270-135, Brazil 
survival rate is the stage of the disease at diagnosis, which is used to assess the patient's possibilities of recovery. ${ }^{3}$

Few studies have been conducted to verify the survival rate of patients diagnosed with bowel cancer. Therefore, the present study aims to perform an assessment of the survival rate in cases of intestinal tumors at Hospital Universitário Alzira Vellano, in the municipality of Alfenas, state of Minas Gerais (MG), Brazil.

\section{Material and Methods}

The present is is a retrospective and observational study performed through data collection from the Pathology Laboratory and from medical records of the aforementioned hospital. A search was conducted regarding the anatomopathological results of intestinal tumors diagnosed in patients of different genders from 2007 to 2016.

The study was approved by the Ethics and Human Research Committee at Universidade José do Rosário Vellano (UNIFENAS) under no. 2,523,421.

The data collected from medical records were plotted in Excel (Microsoft Corp., Redmond, WA, US) spreadsheets to be later statistically distributed or represented in graphs. The absolute frequency and the percentages were obtained. The age ranges were divided into five groups of 12 years each.

The date of completion of the therapy in the medical record or even death records of the studied patients were checked to assess the survival rate. We attempted to contact the patients or their relatives to gather information about those who did not undergo a proper follow-up until the end of the treatment because they no longer came to the hospital for medical care. Regarding these patients, the survival outcome was only documented when contact was successful, and no record was made regarding the survival of the noncontacted patients.

The patients were sorted according to how long they lived after being diagnosed with cancer, which can be from 1 to 5 years. Patients who lived longer than five years were considered cured.

A Chi-squared test was used at a nominal level of $5 \%$ of significance. The statistical analysis was performed using the R software (R Foundation for Statistical Computing, Vienna, Austria) ${ }^{8}$

\section{Results}

During the study period, 128 cases of colorectal cancer were recorded.

Regarding gender, the incidence in males was higher (52.3\%) compared to that in females (47.7\%) (-Table 1).

The age of the patients ranged from 25 to 91 years. However, about $83 \%$ were older than 51 years of age (-Table 1).

The most frequent types of cancer in both genders were of the colon, rectum and sigmoid (-Figure 1). There was a single case of a man presenting two distinct types, rectal and anal cancer together.
Table 1 Survival rate according to age group, tumor location, and staging in men and women diagnosed with bowel cancer from 2007 to 2016 at Hospital Universitário Alzira Vellano

\begin{tabular}{|c|c|c|}
\hline Age range in years $(\%)$ & Male (n) & Female (n) \\
\hline 25 to $37(4.8)$ & 0 & 33 \\
\hline 38 to 50 (11.9) & 86 & 13 \\
\hline 51 to $63(27.8)$ & 43 & 29 \\
\hline 64 to $76(35.7)$ & 32 & 50 \\
\hline 77 to 91 (19.8) & 18 & 57 \\
\hline \multicolumn{3}{|l|}{ Location } \\
\hline Anal canal & 0 & 0 \\
\hline Cecum & 33 & 80 \\
\hline Colon & 27 & 23 \\
\hline Duodenum & 0 & - \\
\hline Papilla of Vater & 0 & - \\
\hline Rectum & 46 & 53 \\
\hline Sigmoid & 40 & 31 \\
\hline Cardia & 0 & - \\
\hline Ileocecum & 0 & - \\
\hline Large intestine & 100 & 33 \\
\hline \multicolumn{3}{|l|}{ Stage } \\
\hline T1N0M0 & - & 100 \\
\hline T1N0Mx & 100 & 100 \\
\hline T2N0M0 & - & 100 \\
\hline T2N0Mx & 100 & 100 \\
\hline T3N0M0 & 40 & 29 \\
\hline T3N0Mx & 50 & 62 \\
\hline T3N1M0 & - & 33 \\
\hline T3N1Mx & 44 & 38 \\
\hline T3N2M1 & 0 & 0 \\
\hline T3N2Mx & 11 & 0 \\
\hline T4N0M1 & - & 0 \\
\hline T4N0Mx & 0 & - \\
\hline T4N1M0 & - & 0 \\
\hline T4N1M1 & - & 0 \\
\hline T4N1Mx & 0 & - \\
\hline T4N2Mx & 0 & - \\
\hline T4N3Mx & - & 0 \\
\hline
\end{tabular}

The most frequent stage in both genders was T3N1Mx, followed by T3N0Mx and T3N2Mx (-Figure 2). Regarding stage T3N2Mx, male patients outnumbered female patients by $18 \%$ (-Figure 2 ).

In terms of life expectancy, a survival rate of more than $30 \%$ was observed for both genders (-Figure 3 ). However, it was possible to observe a more significant percentage of deaths in the first year after the diagnosis, with $23 \%$ of deaths reported in women and $25.8 \%$ in men. 


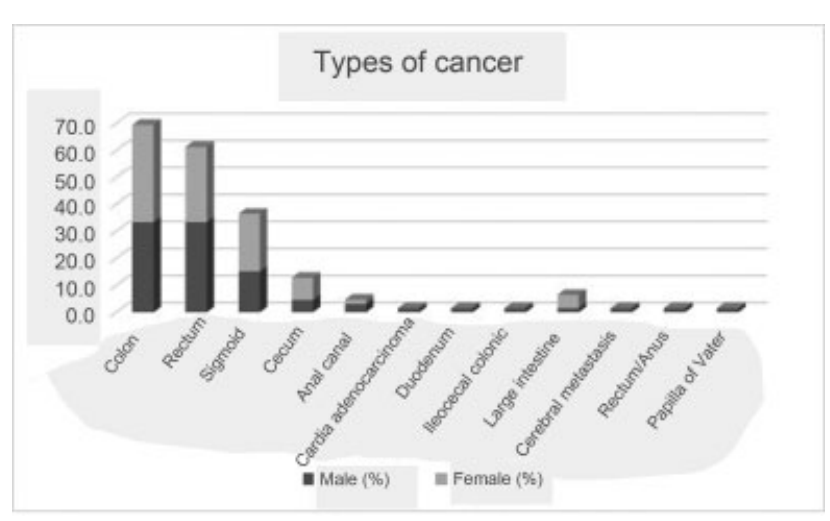

Fig. 1 Types and location of cancer.

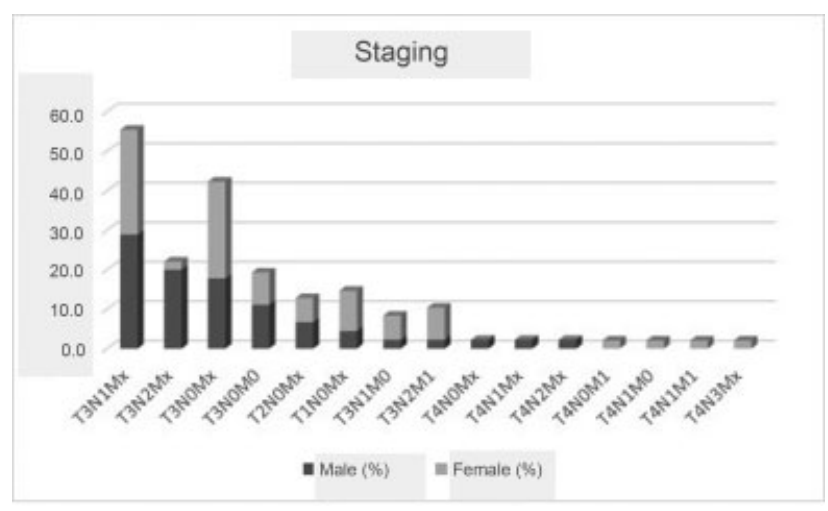

Fig. 2 Staging of cancer.

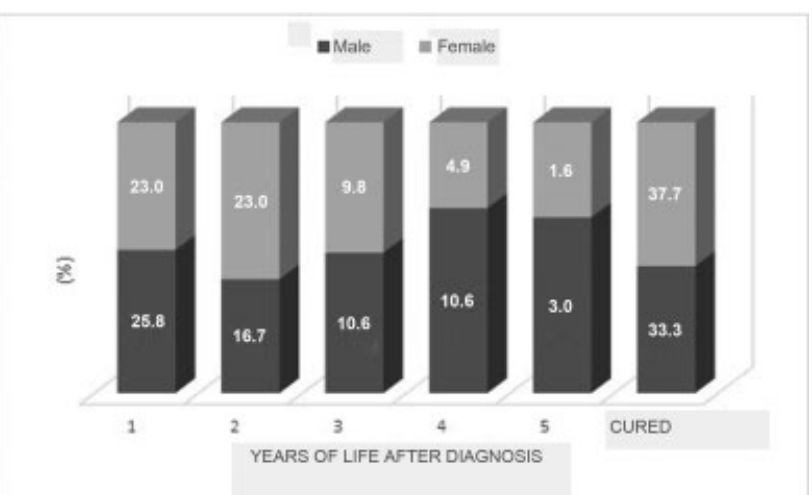

Fig. 3 Years of life after the diagnosis of intestinal tumor of Hospital Alzira Vellano between 2007 and 2016.

The age group between 38 and 50 years had the highest survival rate among men (86\%) and the lowest among women (13\%). Women over 64 years of age had a survival rate greater than $50 \%$. However, the Chi-squared test of independence showed there was no relationship between age and the survival rate of these patients (-Table 2 ).

The survival rate varied according to the specific location of the tumor, reaching $100 \%$ when the tumor was in the large intestine of men, and $0 \%$ among patients with cancer of the anal canal, duodenum, papilla of Vater, gastric cardia, and ileocecum. Rectal cancer, regardless of gender, had a survival rate higher than $45 \%$.
Table $2 p$ Values obtained from the Chi-squared test of independence

\begin{tabular}{|l|l|}
\hline Variables & $p$-value \\
\hline Gender versus survival & $0.4409 \mathrm{~ns}$ \\
\hline Tumor staging versus survival & $0.0792 \mathrm{~ns}$ \\
\hline Tumor location versus survival & $0.0455^{*}$ \\
\hline Age range versus survival & $0.1603 \mathrm{~ns}$ \\
\hline
\end{tabular}

Note: *Significant at the nominal level of $5 \%$ of significance $(p<0.05)$; ns: Not significant at the nominal level of $5 \%$ of significance $(p>0.05)$.

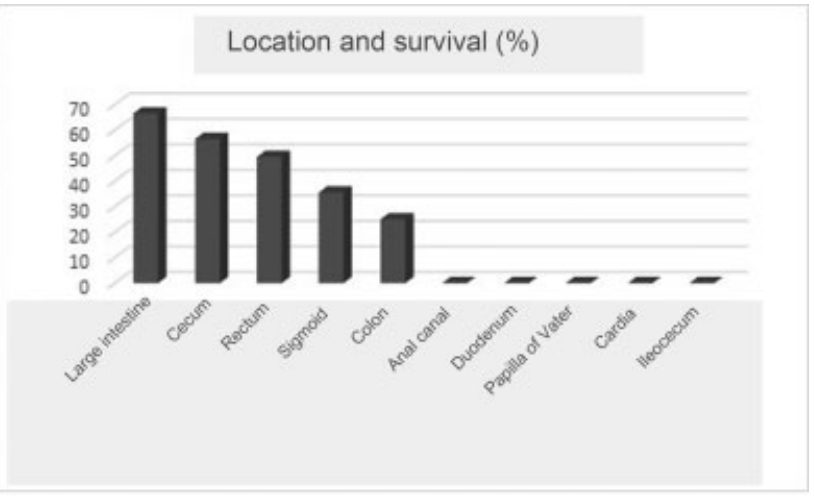

Fig. 4 Location and survival rate of patients diagnosed with intestinal tumor of Hospital Alzira Vellano between 2007 and 2016.

The survival rate among patients with grade 1 or 2 tumor size (T1 or T2) was of $100 \%$. Alternatively, all those who presented grade 4 (T4) had a $0 \%$ survival rate; in other words, they all died within 5 years of the diagnosis.

The other cases were at least of stage-II cancers, that is, a more advanced or later stage of the disease. These cases result in a maximum survival rate of $62 \%$.

After applying the Chi-squared test of independence, we found an association $(p<0.05)$ of the tumor location with the survival rate (-Table 2 ). For the other variables analyzed, there was no association $(p>0.05)$ with the survival rate (-Table 2). Therefore, patients with tumors in the large bowel, cecum and rectum had the highest survival rates (-Figure 4).

All tumors analyzed were adenocarcinomas, most often differentiated modified adenocarcinoma (-Figure 5).

\section{Discussion}

The prevalence of bowel cancer in men compared to women reported in the present study has already been reported by Siegel et al. ${ }^{9}$ According to Coelho, ${ }^{10}$ cancer is a disease that can affect people of both genders and of all age groups. However, the Brazilian National Cancer Institute (Instituto Nacional de Câncer, INCA, ${ }^{2}$ in Portuguese) highlights that colorectal cancer is more common in patients older than 50 years of age, although cases in patients younger than 40 years of age are also reported to a lesser extent. ${ }^{11}$ Alternatively, Kumar et al. ${ }^{12}$ report that the highest incidence 


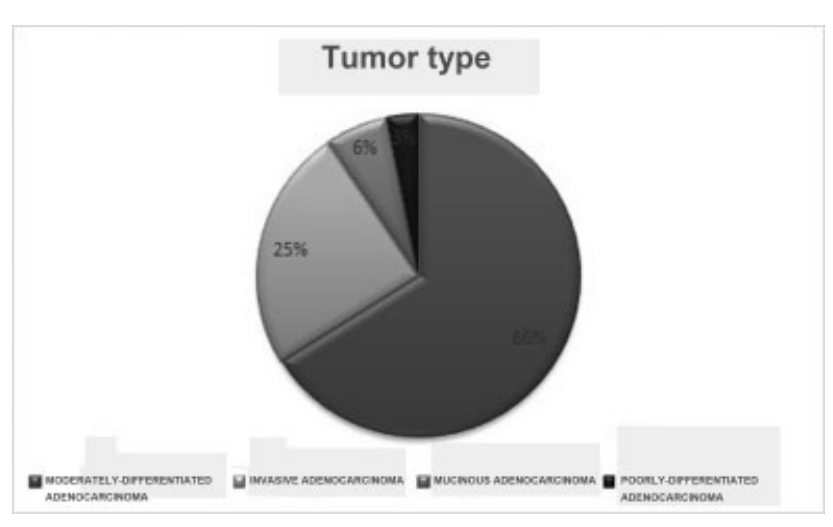

Fig. 5 Types of intestinal tumor related to its staging.

of cancer occurs after 70 years of age, with about $80 \%$ of cases occurring after that age.

Regarding the most frequent types of cancers, Carneiro Neto et al..$^{13}$ found a higher prevalence of rectal and sigmoid tumors in colorectal cancer patients. However, in their study, the most frequent location was the colon, followed by the rectum and sigmoid. It is possible to observe in the reported data that most of the evaluated patients were already in an advanced stage of the disease, mostly $\mathrm{T} 3$ and $\mathrm{T} 4$.

According to Instituto Oncoguia, ${ }^{7}$ recovery is difficult regarding tumors in more advanced stages. This late detection likely led to a high percentage of deaths observed in the first year after the diagnosis in the patients evaluared in the study by Macchetti. ${ }^{14}$

Still according to Instituto Oncoguia, ${ }^{15}$ staging is the process used to evaluate the location, extent and progress of the cancer. This information is used in the planning of the treatment. Therefore, although the cases are different, cancers at the same stage tend to have identical prognoses, and may be treated in the same manner.

Tumor, node, and metastasis (TNM) staging is the system used to evaluate colorectal cancer in patients. According to the American Cancer Society, ${ }^{16}$ the letter T (tumor) refers to the size of the primary tumor and how far it has spread through the wall of the colon or rectum, including the mucosa lining, submucosa, muscularis propria, and the subserosal and serous layers. The $\mathrm{N}$ (node) indicates that the disease has spread to regional lymph nodes, or if there are signs of in-transit metastases. The letter M (metastasis) indicates that metastasis occurs in other parts of the body. The numbers or letters after $\mathrm{T}, \mathrm{N}$, and $\mathrm{M}$ provide details on each of these factors, and the higher the number, the further the disease progresses.

The cases that were at least in stage II of cancer development, that is, a more advanced or late stage of the disease, ${ }^{14}$ showed a maximum of $62 \%$ of survival, below the estimate of $72 \%$ for patients with colon and rectal cancer in the United States reported by the American Cancer Society. ${ }^{16}$

Nevertheless, Fey et al., ${ }^{6}$ in a study with patients with bowel cancer, found, for patients in stages 3 and 4, a survival rate of of $30 \%$ and $5 \%$ respectively. These results are closer to the ones identified in the present study, which may lead to the conclusion that recovery may be related to other factors, such as the country where the treatment has been performed, since both studies were conducted in Brazil.

Most of the cases in the present study were diagnosed at a later stage. According to INCA, ${ }^{2}$ the earlier the identification, the greater the chances of recovery. Thus, the population at risk should take preventive actions. Valadão et al. ${ }^{11}$ also reported late diagnosis in in their study on colorectal cancer patients. The authors pointed to the need for a colorectal cancer screening program, to rapidly identify and increase the survival rate of the patients.

In this regard, Soares and Riul da Silva ${ }^{3}$ reported that intestinal tumor has a slow growth pattern; therefore, it can go unnoticed for several years. When the cancer is in an advanced stage and with little chance of recovery, certain symptoms may or may not appear. Consequently, the observed survival rate is relatively low.

Colorectal cancer affects about one in twenty individuals in high-income countries. In most patients, the disease can be cured if it is diagnosed promptly and there is proper treatment and follow-up. ${ }^{17}$ However, Valadão et al. ${ }^{11}$ emphasize that, as with breast, cervical, and prostate cancer, effective screening decreases the morbimortality associated with colorectal cancer. Screening should be implemented, considering that colorectal cancer represents the third most incident neoplasm in Brazil. It would have a significant impact on reducing cancer-related mortality and public spending. ${ }^{11}$

As observed in the present study, cases in stage 4 typically had a $0 \%$ survival rate: all died within five years of the diagnosis. This was also noted by Cruz, ${ }^{18}$ who evaluated patients younger than 40 years of age with stage- 4 cancer. Moreover, stage- 3 patients also showed a poor survival rate (14.3\%). The study by $\mathrm{Cruz}^{18}$ then proves that age is not related to the survival rate of bowel cancer patients.

However, according to Instituto Oncoguia, ${ }^{7}$ survival rates are based on the previous outcomes of a considerable number of patients who had the disease, making it impossible to predict what will happen to each patient. Therefore, in different studies there may be a variation in the results obtained, since other factors can equally affect a patient's prognosis, such as age, general health status, and the response to the treatment.

As reported by Melo et al., ${ }^{19}$ about $95 \%$ of colorectal tumors are adenocarcinomas, and squamous cell carcinoma, lymphomas, carcinoids, liposarcomas, and leiomyosarcomas are rarely found. These authors pointed out that the progression of adenocarcinoma is slow.

Adenomatous polyps are benign glandular tumors, with potentially malignant epithelial changes. Their development is usually related to the accumulation of genetic changes that result in an imbalance between the proliferation of epithelial cells and apoptosis. The likelihood of an adenoma developing into an aggressive invasive lesion depends on two critical factors: polyp size and level of dysplasia. Predisposition can be associated with lifestyle habits such as a high-fat diet and low vegetable-fiber intake. ${ }^{19}$ 


\section{Conclusion}

In the present study, we verified that there was no independence between the variables tumor location and overall survival rate in the cases of colorectal cancer assessed.

The survival rate of the patients diagnosed with colorectal cancer at Hospital Universitário Alzira Vellano from 2007 to 2016 was low due to delayed diagnosis. Therefore, there is sufficient evidence highlighting the need for interventions for the early diagnosis of this type of tumor.

\section{Conflict of Interests}

The authors have no conflict of interests to declare.

\section{References}

1 Nakashima JP, Koifman RJ, Koifman S. Cancer incidence in the Western Amazon: population-based estimates in Rio Branco, Acre State, Brazil, 2007-2009. Cad Saude Publica 2012;28(11): 2125-2132

2 INCA - Instituto Nacional de Câncer. Estatísticas de câncer. Brasília: Ministério da saúde, 2020. Available from: https:// www.inca.gov.br

3 Soares EM, Riul da Silva S. Perfil de pacientes com câncer ginecológico em tratamento quimioterápico. Rev Bras Enferm 2010;63(04):517-522

4 Nicolussi AC, Sawada NO. Qualidade de vida de pacientes com câncer colorretal em terapia adjuvante. Acta Paul Enferm 2009;22(02): 151-161.From: https://doi.org/10.1590/S0103-21002009000200007

5 Jorge LLR, da Silva SR. Evaluation of the quality of life of gynecological cancer patients submitted to antineoplastic chemotherapy. Rev Lat Am Enfermagem 2010;18(05):849-855

6 Fey A, Teixeira JVC, Schinko FB, Vieira AM, Becker I. Perfil epidemiológico e evolução dos pacientes com câncer do cólon e reto atendidos no Hospital Regional Alto Vale no ano de 2008. Arquivos Catarinenses de Medicina -ACM 2010;39(04):62-67
7 Instituto Oncoguia. Estadiamento do Câncer Colorretal. 2019. Available from: http://www.oncoguia.org.br/conteudo/estadiamento-do-cancer-colorretal/541/179/

8 R Core Team. R: A Language and Environment for Statistical Computing. Vienna: R Foundation for Statistical Computing; 2018

9 Siegel RL, Miller KD, Jemal A. Cancer statistics, 2020. CA Cancer J Clin 2020;70(01):7-30

10 Coelho JCU. Aparelho Digestivo: clínica e cirúrgica. Rio de Janeiro: Atheneu; 2006

11 Valadão M, Leal RA, Barbosa LC, Carneiro M, Muharre RJ. Perfil dos pacientes portadores de câncer colorretal operados em um hospital geral: necessitamos de um programa de rastreamento acessível e efetivo. Rev Bras Coloproctol 2010;30:160-163. From: https://doi.org/10.1590/S0101-98802010000200006

12 Kumar V, Abbas A, Aster JC. Robbins Patologia Básica. 9th ed. Rio de Janeiro: Elsevier; 2013

13 Carneiro Neto JD, Barreto JBP, Freitas NS, Queiroz MA. Câncer colorretal: características clínicas e anatomopatológicas em pacientes com idade inferior a 40 anos. Rev Bras Coloproctol 2006;26:430-435. From: https://doi.org/10.1590/S0101-98802006000400009

14 Macchetti AH. Estadiamento do câncer de mama diagnosticado no sistema público de saúde de São Carlos. Medicina (B Aires) 2007; 40:394-402. From: https://doi.org/10.11606/issn.2176-7262. v40i3p394-402

15 Instituto Oncoguia. Estadiamento do Câncer. 2020. Available from: http://www.oncoguia.org.br/conteudo/estadiamento/4795/1/

16 ACS - American Cancer Society. Colorectal Cancer Stages. 2018. Available from: https://www.cancer.org/cancer/colon-rectalcancer/detection-diagnosis-staging/staged.html

17 Jeffery M, Hickey BE, Hider PN. Follow-up strategies for patients treated for non-metastatic colorectal cancer. Cochrane Database Syst Rev 2019;9:CD002200. From: 10.1002/14651858.CD002200. pub3

18 Cruz GMG. Câncer colorretal em pacientes com menos de 40 anos de idade. Rev Bras Coloproctol 1991;11:19-24

19 Melo MM, Cury PM, Ronchi LS, Gonçalves-Filho FdeA, Cunrath GS, Netinho JG. Terminal ileum of patients who underwent colonoscopy: endoscopic, histologic and clinical aspects. Arq Gastroenterol 2009;46(02):102-106 